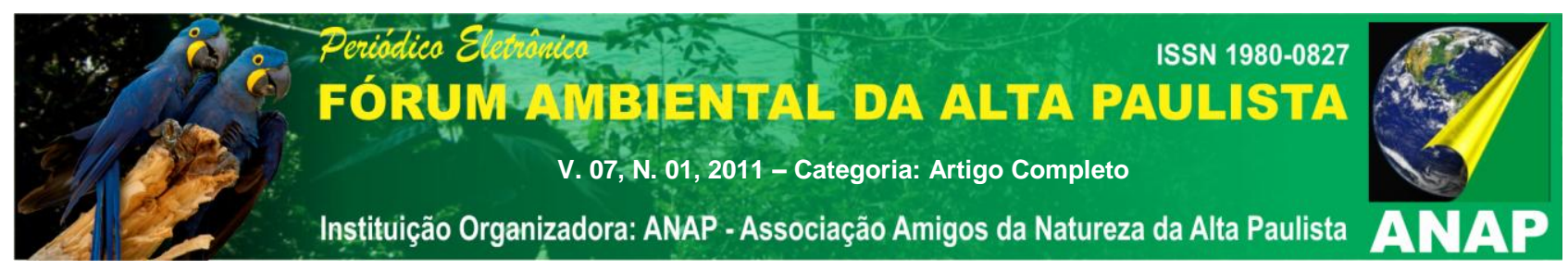

\title{
EMPREGO DE AQUECEDORES DE ÁGUA DE BAIXO CUSTO PARA REALIZAÇÃO DA ROTINA HIGIÊNICA EM ORDENHA MANUAL DE LEITE BOVINO
}

\author{
Matheus Choueri ${ }^{1}$ \\ Camila Pires Cremasco Gabriel ${ }^{2}$ \\ Luís Roberto Almeida Gabriel Filho ${ }^{3}$ \\ Daniel dos Santos Viais Neto ${ }^{4}$
}

RESUMO: O Pequeno produtor de leite bovino tem grande dificuldade em adequar sua produção aos parâmetros da Instrução Normativa $\mathrm{n}^{\circ}$. 51 pela necessidade de alto investimento em equipamentos de aquecimento de água que deve ser utilizada na rotina higiênica da produção. A qualidade do leite é definida por fatores relativos ao manejo dos animais (sanidade e alimentação) e práticas de higiene antes, durante e depois da ordenha. Parte desse processo de higiene é realizada com água de qualidade boa em temperatura fria e quente $\left(50-60^{\circ} \mathrm{C}\right)$ aquecida por energia usual (elétrica e gás GLP), para limpeza dos aparelhos e utensílios utilizados na ordenha, o que interfere nos resultados financeiros do produtor. O presente trabalho preocupou-se em utilizar uma proposta de aquecimento da água através da implantação de sistemas híbridos de aquecedores (elétrico-solar, elétrico-gás ou solar-gás) na unidade produtiva. Foram utilizadas análises microbiológicas em amostras de leite coletados após a lavagem dos utensílios de ordenha manual ser realizada utilizando água aquecida pelos sistemas apresentados. Os resultados das análises laboratoriais apresentaram considerável redução no NMP/mL de leite para Coliformes a $35 \stackrel{\circ}{\circ}$ para as amostras não pasteurizadas colhidas após a realização das lavagens dos materiais de ordenha manual

\footnotetext{
1 Tecnólogo em Agronegócio. matheuschoueri@bol.com.br.

${ }^{2}$ Licenciada em Matemática (FCT/UNESP), Mestre em Matemática Pura (DM/UFSCar), Doutora em Agronomia/Energia na Agricultura (FCA/UNESP) e Pós-doutoranda em Bioestatística (IB/UNESP), Professora Assistente da FATEC Presidente Prudente.camila@fatecpp.edu.br.

${ }^{3}$ Licenciado em Matemática (FCT/UNESP), Mestre em Matemática Pura (ICMC/USP), Doutor em Agronomia/Energia na Agricultura (FCA/UNESP) e Pós-doutorando em Agronomia/Energia na Agricultura (FCA/UNESP), Professor Assistente Doutor da CET/UNESP - Tupã/SP. gabrielfilho@tupa.unesp.br.

${ }^{4}$ Licenciado e Bacharel em Matemática (ICMC/USP), Mestre em Matemática Pura (ICMC/USP) e Doutorando em Agronomia/Irrigação e Drenagem (FCA/UNESP), Professor Associado da FATEC - Presidente Prudente. dvneto@fatecpp.edu.br.
} 
ser realizada utilizando água aquecida pelo sistema híbrido composto pelo aquecedor solar e pelo aquecedor a gás. Este tipo de sistema de aquecimento de água permite aos pequenos produtores de leite adequarem-se a IN 51, com baixo custo de investimento principalmente em localidades desprovidas de fornecimento de energia elétrica.

Palavras-chave: Aquecimento de água, ordenha manual, produção de leite

\section{INTRODUÇÃO}

Somente no estado de São Paulo (Brasil) existem 1.636.929 vacas em estado produtivo, gerando cerca de 1.744.179 litros de leite ao ano. A maior parte desse rebanho está dividida entre milhares de pequenas propriedades com recursos produtivos escassos.

Nos últimos anos várias pesquisas foram feitas sobre a conservação do leite após sua obtenção, bem como as condições ideais para higiene e controle sanitário. $O$ Ministério da Agricultura, Pecuária e Abastecimento (MAPA), publicou a Instrução Normativa $n^{0} .51$ de 18 de setembro de 2002 (IN 51) estabelecendo parâmetros de controle sanitário para a produção, comercialização e transporte de leite no território nacional.

A IN 51 destaca que para a higiene de utensílios para produção de leite deve ser utilizada água de boa qualidade com temperatura ente 50 e $60 \stackrel{\circ}{\circ}$ todos os dias nos intervalos de ordenha.

O leite no momento da coleta é retirado com alguns utensílios de ordenha que podem contaminá-lo antes de chegar aos tanques comunitários de resfriamento. Este processo reduz a qualidade do produto comercializado e prejudica financeiramente 0 produtor rural no momento da venda.

O item 2.1.1 da Instrução Normativa $n^{0} .51$ define o leite como "o produto oriundo da ordenha completa e ininterrupta, em condições de higiene, de vacas sadias, bem alimentadas e descansadas".

O leite, por natureza, é um alimento rico em nutrientes contendo proteínas, carboidratos, gorduras, vitaminas e sais minerais. Sua qualidade é um dos temas mais 


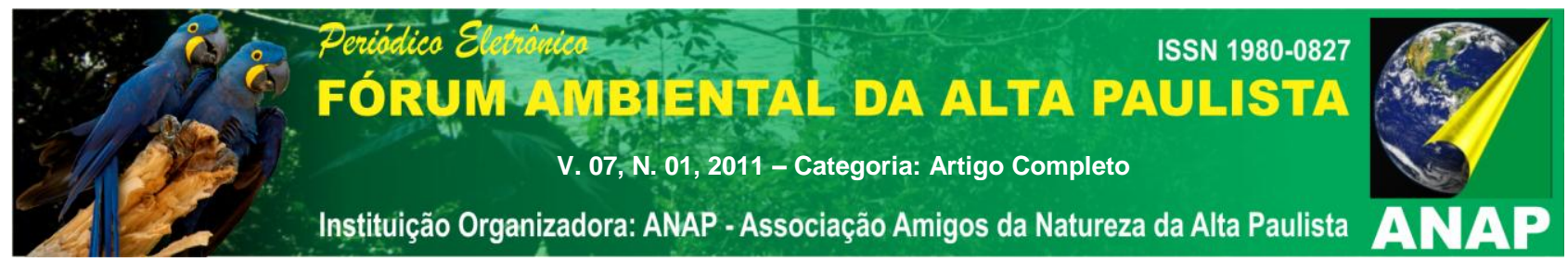

discutidos atualmente dentro do cenário nacional de produção leiteira. (GUERREIRO et al. 2005)

O leite tipo A é caracterizado pela forma de extração que deve ser mecanizada, sem qualquer contato manual e seguindo severos padrões de higiene. Não pode apresentar um número de bactérias por mililitro $(\mathrm{mL})$ superior a 500 unidades.

Para o leite tipo B a ordenha pode ser mecanizada ou manual, desde que seguidos os padrões determinados pela IN 51, apresentando no máximo 40.000 unidades de bactérias por $\mathrm{mL}$.

O leite tipo $\mathrm{C}$ contém o maior número de bactérias entre os tipos de leite. Pode apresentar uma quantidade de bactérias não superior a 100.000 unidades por mL. A ordenha geralmente é feita manualmente. E para nenhum dos três tipos é aceita a presença de aditivos.

Em estudos realizados por Adesiyun et al. (1997), constatou-se que das amostras de leite cru coletadas em tanques de expansão, 47\% apresentaram-se positivas para Escherichia coli, sendo que, somente $5 \%$ destas, estavam associadas à mastite subclínica. Isto reforça a importância da adoção de práticas de higiene na obtenção do leite. (PICININ, 2010)

Para Bressan e Martins (2003) a produção de alimentos seguros, saudáveis e nutritivos, em bases sustentáveis e competitivas, é um dos fundamentos da segurança alimentar.

Fonseca et al. (2001, apud Bressan e Matins, 2003), como matéria-prima, o leite deve apresentar qualidade, tanto em seus aspectos físico-químicos, como organolépticos, ausência de agentes patogênicos, reduzida carga microbiana, baixa contagem de células somáticas e ausência de agentes contaminantes.

Forsythe (2002) descreve os coliformes como bactérias gram-negativas, anaeróbicas facultativas em forma de bastonetes. Também conhecidos como grupo coliaerogenes. O grupo dos coliformes inclui espécies do gênero Escherichia, Klebsiella, Enterobacter e Citrobacter, além de E. coli.

Com a Resolução no 12, de 2 de janeiro de 2001, da Agência Nacional de Vigilância Sanitária (ANVISA), o Ministério da Saúde, adotou a denominação coliformes a 


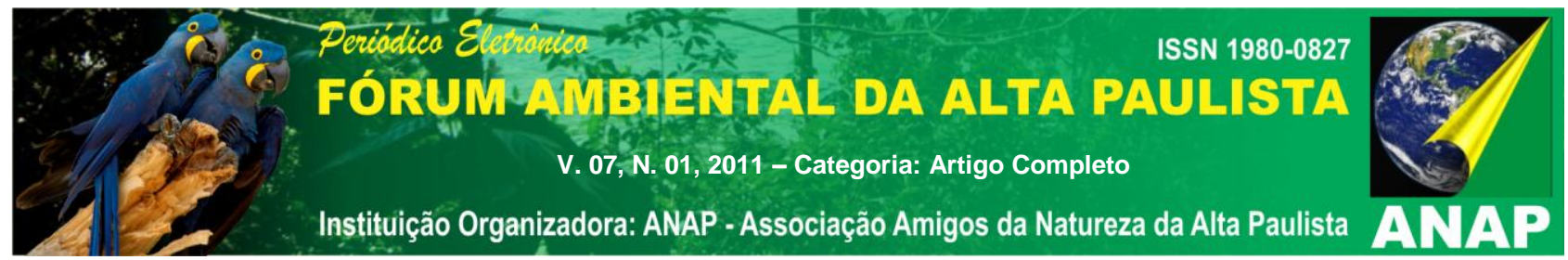

$45^{\circ} \mathrm{C}$, considerando os padrões "coliformes de origem fecal" e "coliformes termo tolerantes" como equivalentes a coliformes a $45^{\circ} \mathrm{C}$. (SILVA; CAVALLI e OLIVEIRA, 2006)

Os coliformes fecais são definidos como coliformes capazes de fermentar a lactose em meio $\mathrm{EC}$, com produção de gás, no período de 48 horas, a $45,5 \stackrel{\circ}{ } \mathrm{C}$ com exceção dos isolados de moluscos, 44,5ํㅡ (FORSYTHE, 2002).

A proposta deste trabalho foi potencializar a higiene dos utensílios utilizando um sistema de aquecimento de água de baixo custo composto por materiais recicláveis que utiliza energia alternativa e, com isso, manter a qualidade do leite produzido, realizando as lavagens recomendadas pela IN 51.

\section{MATERIAIS E MÉTODOS}

\subsection{Materiais}

Os sistemas de aquecimento utilizados neste trabalho foram instalados no sítio Nossa Senhora de Lourdes, localizado no município de Mirante do Paranapanema-SP. Cada conjunto foi formado com um par de cada um dos seguintes sistemas de aquecimento:

O aquecedor solar feito com material reciclável foi instalado no estábulo da propriedade, seguindo os padrões e especificações do Laboratório de Conforto Térmico e Ambiência (LCTA) pertinente ao Campus Experimental da UNESP de Tupã. Este laboratório foi construído a partir do projeto intitulado "Aplicação da lógica fuzzy para avaliação do conforto térmico de aquecedores solares compostos por embalagens recicláveis" - Processo 480985/2008-1 - Edital MCT/CNPq 14/2008 - Universal.

O sistema elétrico utilizado foi composto por materiais de baixo valor de aquisição e que possibilitassem a realização do aquecimento da água por acumulação, sendo: um aparelho ebulidor tipo mergulhão de 39 centímetros grande e uma panela tipo caldeirão.

O sistema a gás também foi composto por material alternativo de uso doméstico a fim de minimizar o custo de aquisição. Sendo formado por um botijão de gás de cozinha, um fogão mono boca de alta pressão e uma panela tipo caldeirão. 

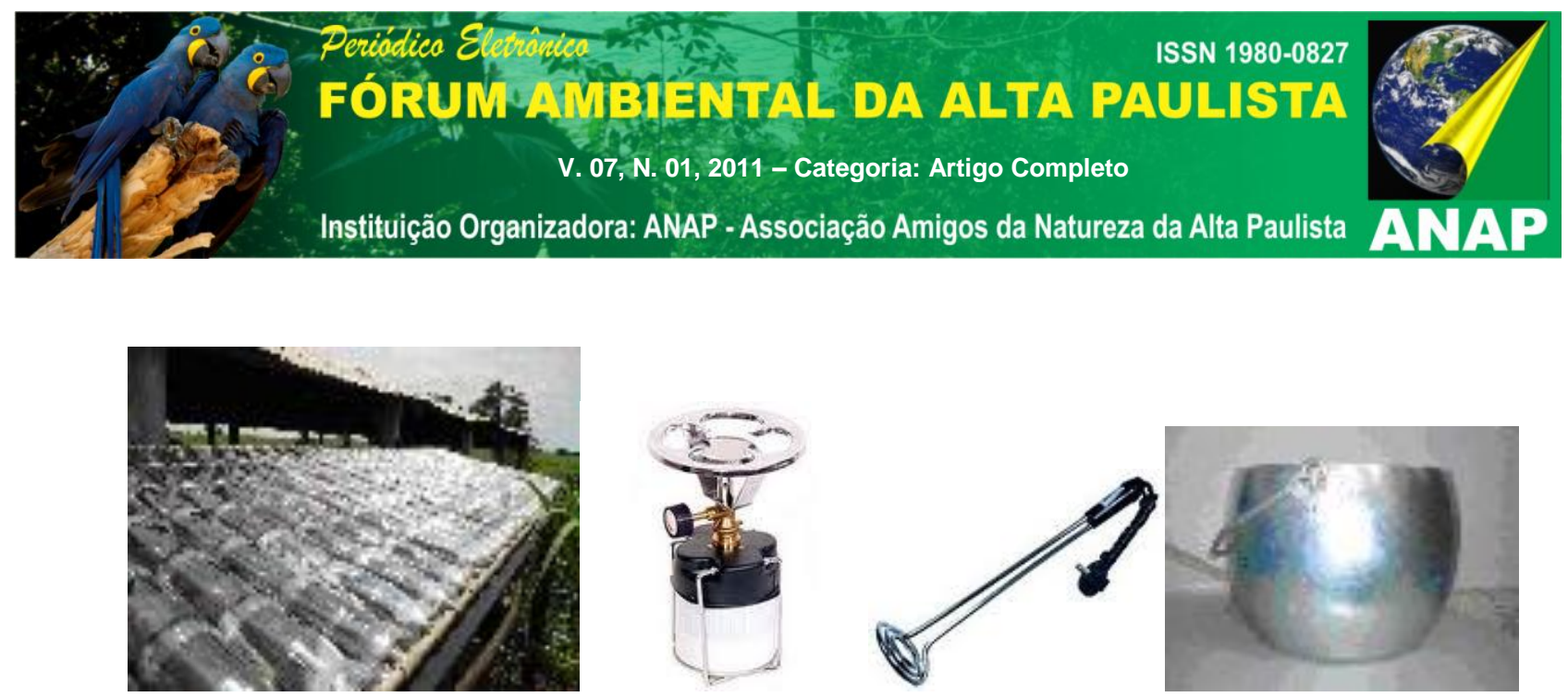

Figura 1. Sistemas de aquecimento de água utilizados para realização das lavagens.

\subsection{Métodos}

A análise visou avaliar a eficiência dos três sistemas propostos, verificando a quantidade de microorganismos remanescentes no leite após as lavagens tendo como controle uma amostra que não foi utilizado qualquer um dos sistemas. Para a realização das análises do experimento, foi utilizado como objeto de estudo o leite bovino ordenhado manualmente pelo produtor. Foram colhidas quatro amostras do leite para análise laboratorial.

As análises das amostras foram realizadas no Laboratório de Análises de Alimentos pertencente a Faculdade de Farmácia da Universidade do Oeste Paulista (UNOESTE). O método utilizado para a verificação de existência de microorganismos (Coliformes a $35^{\circ} \mathrm{C}$ e Coliformes a $45^{\circ} \mathrm{C}$ ) foi o de Tubos Múltiplos que informa o número mais provável por mililitro de leite $(\mathrm{NMP} / \mathrm{mL})$. O processo de verificação por Tubos Múltiplos é realizado como análise rápida, pois o tempo total utilizado para se obter os resultados não ultrapassa 48 horas.

Para cada uma das amostras, separou-se $25 \mathrm{~g}$ (gramas) do conteúdo da amostra, que foi homogeneizado em água peptonada 0,1\% esterilizada durante 1 minuto. Diluições décimas a partir da diluição 10-1 a 10-3 foram preparadas em tubos contendo 9,0 mL de água peptonada $0,1 \%$.

Alíquotas de $1,0 \mathrm{~mL}$ de cada diluição foram transferidas para séries de três tubos contendo CLS com tubos de Durham invertidos. Os tubos foram incubados a $35{ }^{\circ} \mathrm{C}$ durante 24 e 48 h, e uma alçada de cada tubo apresentando crescimento e produção de 


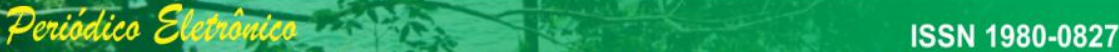

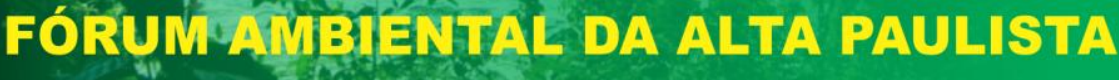 \\ V. 07, N. 01, 2011 - Categoria: Artigo Completo \\ Instituição Organizadora: ANAP - Associação Amigos da Natureza da Alta Paulista}

gás foi semeada em tubos contendo $10 \mathrm{~mL}$ de CLBVB e E.C., com tubos de Durham invertidos.
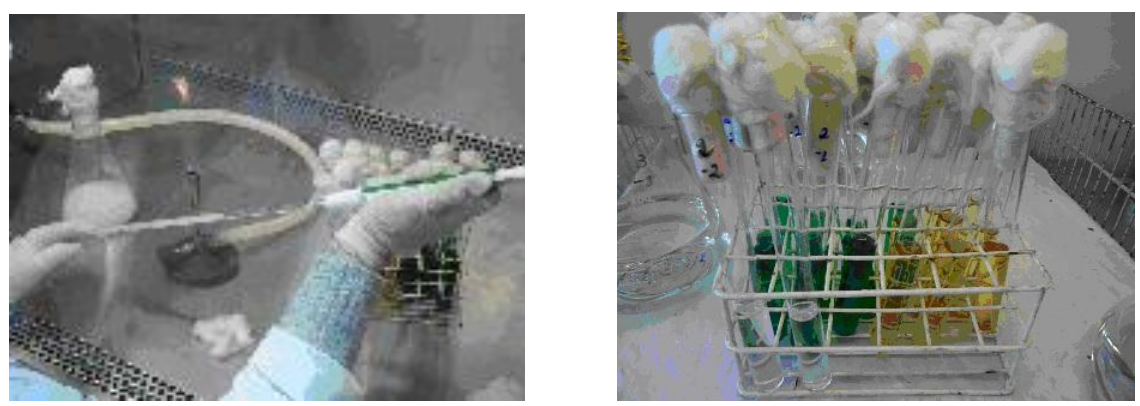

FIGURA 2. Etapas do processo de diluição das amostras.

\section{RESULTADOS E DISCUSSÃO}

\subsection{Resultados Laboratoriais}

Os resultados das análises apresentam o Número Mais Provável (NMP) de coliformes presentes na amostra. Não sendo o número exato de microorganismos contidos no material colhido. Nota-se que os valores de referência adotados pelo Laboratório que realizou as análises seguem a Portaria 01/1987 para leite pasteurizado tipo C. Todas as amostras submetidas às análises foram retiradas de leite cru (não pasteurizado). O tempo transcorrido entre a ordenha e a coleta (e posterior refrigeração para transporte ao laboratório) não superou 30 minutos após o contato do leite com os latões.

Tabela 1. Resultados das análises laboratoriais.

\begin{tabular}{lcc|cc}
\hline & \multicolumn{2}{|c|}{ Resultados (NMP/mL) } & \multicolumn{2}{c}{ Valores de Referência * (NMP/mL) } \\
Sistema Aquecimento & $\begin{array}{c}\text { Coliformes } \\
\text { a 35 }{ }^{\circ} \mathbf{C}\end{array}$ & $\begin{array}{c}\text { Coliformes } \\
\text { a 45 }{ }^{\circ} \mathbf{C}\end{array}$ & $\begin{array}{c}\text { Coliformes } \\
\text { a 35 }{ }^{\circ} \mathbf{C}\end{array}$ & $\begin{array}{c}\text { Coliformes } \\
\text { a 45 }{ }^{\circ} \mathbf{C}\end{array}$ \\
\hline Controle (sem lavagem) & $\geq 2.400$ & $<3$ & Máximo 10 & Máximo 2 \\
Elétrico-gás & $\geq 1.100$ & $<3$ & Máximo 10 & Máximo 2 \\
Solar-elétrico & 460 & $<3$ & Máximo 10 & Máximo 2 \\
Solar-gás & 93 & $<3$ & Máximo 10 & Máximo 2 \\
\hline
\end{tabular}




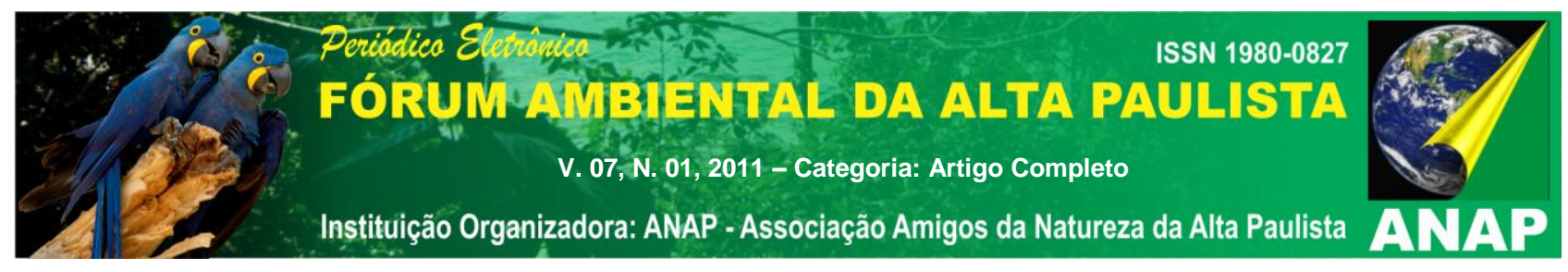

* Segundo Portaria 01/1987 para leite pasteurizado tipo C

Para todos os resultados o NMP de Coliformes a $45 \stackrel{\circ}{\circ}$ (Coliformes fecais) manteve-se o mesmo. Isto não significa que os sistemas não sejam eficientes para matar este tipo de microrganismo, pois se sabe que a presença de Coliformes a $45{ }^{\circ} \mathrm{C}$, não prova a contaminação de origem fecal (SILVA; CAVALLI e OLIVEIRA, 2006).

Pelos resultados das análises, o sistema híbrido que apresentou melhor eficiência para a redução do $\mathrm{NMP} / \mathrm{mL}$ dos microrganismos estudados foi o sistema composto pelo aquecedor solar feito com materiais recicláveis e pelo aquecedor a gás.

\subsection{Custos dos Aquecedores}

Os aquecedores foram utilizados em pares para que não houvesse falta de energia para o aquecimento da água utilizada nas lavagens dos materiais de ordenha. A ordem de uso de cada par formou um sistema híbrido de aquecimento. Os três sistemas foram:

1) Sistema elétrico mais apoio do sistema a gás;

2) Sistema solar feito com material reciclável com apoio do sistema a gás e;

3) Sistema solar feito com material reciclável com apoio do sistema elétrico.

Os custos dos aquecedores foram formados a partir dos orçamentos referentes a cada um dos sistemas. Os valores são datados de outubro de 2010, ano em que foram adquiridos os materiais.

Tabela 2. Investimento necessário para o sistema híbrido 1 (elétrico-gás).

Descrição Quantidade Unidade Valor




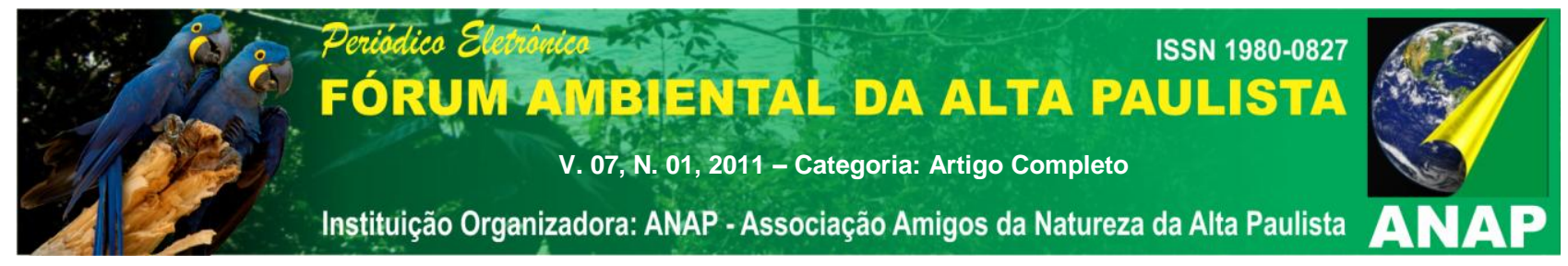

\begin{tabular}{lllrr}
\hline & & & Unitário (R\$) & \multicolumn{1}{c}{ Total (R\$) } \\
\hline Aparelho Ebulidor & 1 & unid. & 30,00 & 30,00 \\
Caldeirão & 1 & unid. & 70,00 & 70,00 \\
Botijão Gás & 1 & unid. & 100,00 & 100,00 \\
Fogão Mono boca & 1 & unid. & 79,90 & 79,90 \\
\hline Total & & & & $\mathbf{2 7 9 , 9 0}$ \\
\hline
\end{tabular}

unid - unidade

Fonte: Orçamento Local.

Tabela 3. Investimento necessário para o sistema híbrido 2 (solar-gás).

\begin{tabular}{lccrr}
\hline \multicolumn{1}{c}{ Descrição } & Quantidade & Unidade & $\begin{array}{c}\text { Valor } \\
\text { Unitário (R\$) }\end{array}$ & \multicolumn{1}{c}{$\begin{array}{c}\text { Valor } \\
\text { Total (R\$) }\end{array}$} \\
\hline Tubos e conexões em PVC & 78 & $\mathrm{~m}$ & 1,65 & 128,70 \\
Reservatório Água & 1 & unid. & 215,00 & 215,00 \\
Ferramentas e tinta & 1 & unid. & 79,55 & 79,55 \\
Caldeirão & 1 & unid. & 70,00 & 70,00 \\
Botijão Gás & 1 & unid. & 100,00 & 100,00 \\
Fogão Monoboca & 1 & unid. & 79,90 & 79,90 \\
\hline Total & & & & $\mathbf{6 7 3 , \mathbf { 1 5 }}$ \\
\hline
\end{tabular}

m- metro

unid. - unidade

Fonte: Orçamento Local.

Tabela 4. Investimento necessário para o sistema híbrido 3 (solar-elétrico).

\begin{tabular}{lccrrr}
\hline \multicolumn{1}{c}{ Descrição } & Quantidade & Unidade & \multicolumn{1}{c}{$\begin{array}{c}\text { Valor } \\
\text { Unitário (R\$) }\end{array}$} & \multicolumn{1}{c}{$\begin{array}{c}\text { Valor } \\
\text { Total (R\$) }\end{array}$} \\
\hline Tubos e conexões em PVC & 78 & $\mathrm{~m}$ & 1,65 & 128,70 \\
Reservatório Água & 1 & unid. & 215,00 & 215,00 \\
Ferramentas e tinta & 1 & unid. & 79,55 & 79,55 \\
Caldeirão & 1 & unid. & 70,00 & 70,00 \\
Aparelho Ebulidor & 1 & unid. & 30,00 & 30,00 \\
\hline Total & & & & $\mathbf{5 2 3 , 2 5}$ \\
\hline
\end{tabular}

$\mathrm{m}-$ metro

unid. - unidade

Fonte: Orçamento Local.

Os custos de operação dos sistemas híbridos são formados pelos valores mensais dos insumos necessários para a operação de cada sistema.

Cada sistema híbrido utiliza diferentes insumos conforme mostra a Tabela 5. 


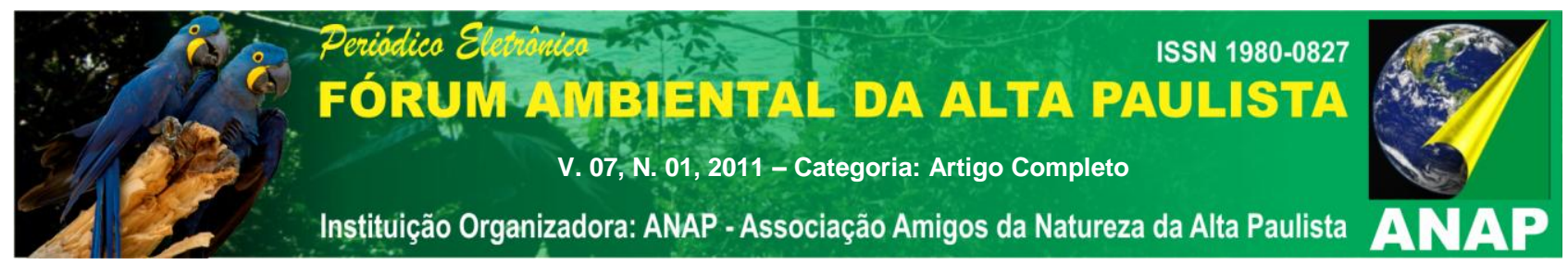

Tabela 5. Custo de operação dos sistemas híbridos de acordo com o insumo necessário.

\begin{tabular}{lrrr}
\hline \multicolumn{1}{c}{ Insumos } & Sistema 1 & Sistema 2 & Sistema 3 \\
\hline Energia Elétrica (rede) R $\$$ /Mês & 30,00 & 0,00 & 30,00 \\
Gás (GLP) R\$/Mês & 40,00 & 40,00 & 0,00 \\
Depreciação R\$/Mês & 23,33 & 56,10 & 43,60 \\
Juros R\$/Mês & 14,00 & 33,66 & 26,16 \\
\hline Total Mensal (R\$) & $\mathbf{1 0 7 , 3 3}$ & $\mathbf{1 2 9 , 7 6}$ & $\mathbf{9 9 , 7 6}$ \\
\hline
\end{tabular}

Fonte: pesquisa.

Cada sistema apresenta um custo de operação distinto, pois utilizam insumos diferentes. Os valores informados são referentes a um mês de operação. Para os insumos energia elétrica e gás foram utilizados os valores praticados em maio de 2011 na região de Mirante do Paranapanema.

A depreciação é apresentada, pois é parte do valor necessário para manutenção e reparos eventuais dos sistemas, sendo completado pelos juros. Para o cálculo do valor da depreciação foi utilizado o valor total de cada sistema dividido pela quantidade de meses do ano (12). Para cálculo dos juros foi necessário obter a taxa de juros referente a um mês (utilizando 6\% ao ano) e multiplicá-la pelo valor total do sistema.

\section{CONCLUSÃO}

A pesquisa teve como finalidade oferecer um sistema de aquecimento barato e eficiente, para ser utilizado por pequenos produtores rurais durante o processo de ordenha, adequando-se a IN 51.

A avaliação da eficiência na remoção de microrganismos (Coliformes a $35{ }^{\circ} \mathrm{C}$ e Coliformes a $45{ }^{\circ} \mathrm{C}$ ) dos equipamentos que entram em contato com o leite, reduzindo a contaminação teve como melhor resultado o Sistema Híbrido 2 composto pelo aquecedor solar de materiais recicláveis e pelo aquecedor a gás.

Os aquecedores estudados tiveram resultados positivos para redução de microrganismos. Estes sistemas híbridos podem ser utilizados por qualquer produtor por 


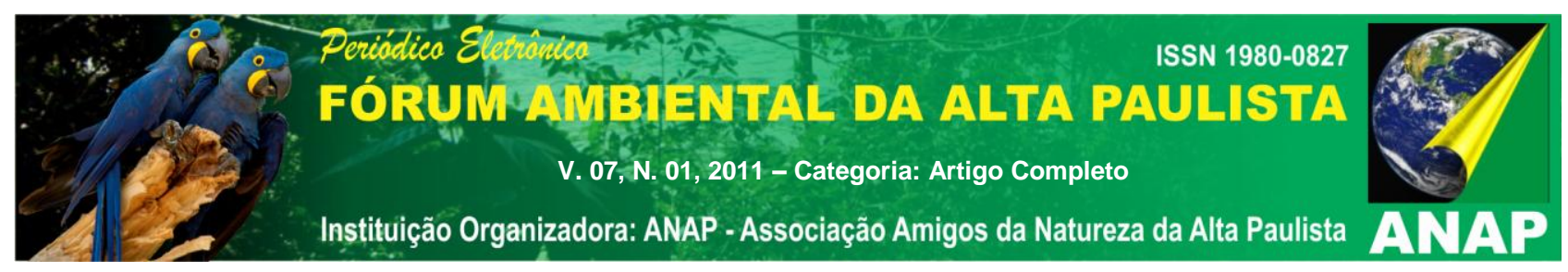

possuírem valor de aquisição relativamente baixo em comparação a sistemas convencionais de aquecimento de água.

\section{REFERÊNCIAS}

BRESSAN, Matheus; MARTINS, Marcelo C. Segurança alimentar na cadeia produtiva do leite e alguns de seus desafios. Artigo técnico, 2003. Disponível em: <http://www.cnpgl.embrapa.br/nova/sala/artigos/artigolinha.php?id=3>. Acesso em: 15 out. 2010.

FORSYTHE, Stephen J. Microbiologia da segurança alimentar. Porto Alegre: Artmed, 2002.

GUERREIRO, Paola K.; MACHADO, Márcia R. Fragoso; BRAGA, Gilberto C.; GASPARIANO, Eliane; FRANZENER, Alexandra da S. Martinez. Qualidade microbiológica de leite em função de técnicas profiláticas no manejo de produção. In CIÊNCIA E AGROTECNOLOGIA: Janeiro, vol. 29, no 1, fev 2005. Disponível em: $<$ http://www.scielo.br/scielo.php?script=sci_arttext\&pid=S1413$70542005000100027 \&$ lang=pt>. Acesso em: 28 set. 2010.

MAPA. Informações gerais sobre a Instrução normativa ํㅜ . 51. Disponível em: <http://www.agricultura.gov.br/>. Acesso em: 27 març. 2010.

PICININ, Lídia C. Almeida. Quantidade e qualidade da água na produção de bovinos de leite. Artigo técnico, 2010. Disponível em: <http://pt.engormix.com/MA-pecuarialeite/administracao/artigos/quantidade-qualidade-agua-producao-t305/124-p0.htm>. Acesso em: 28 ago 2010.

SILVA, M. P.; CAVALLI, D. R.; OLIVEIRA, T. C. R. M. Avaliação do padrão coliformes a 45C e comparação da eficiência das técnicas dos tubos múltiplos e Petrifilm EC na detecção de coliformes totais e Escherichia coli em alimentos. In. CIÊNCIA E TECNOLOGIA DE ALIMENTOS. Abr/Jun, vol. 26 n‥2 2006. Disponível em: <http://www.scielo.br/scielo.php?script=sci_arttext\&pid=S0101-20612006000200018> Acesso em: 02 mai 2011. 